\title{
Vascular compromise and hemodynamics in pulmonary arterial hypertension: Model predictions
}

\author{
Zoheir Bshouty MD PhD FRCPC
}

\begin{abstract}
METHODS
Pulmonary circulation model

A computer model of the normal pulmonary circulation based on animal $(\mathrm{dog})$ data obtained in the literature was previously developed by Bshouty and Younes (for details see references [S1, S2]). The model is described briefly and only details not included in the original model development will be included here. The original model is a multibranch model that bifurcates sequentially starting from the pulmonary artery (PA) up to eight (four generations) precapillary and capillary channels. The model was later modified to include five generations ending in sixteen precapillary and capillary channels (Figure S1). On the venous side, the vessels converge and reunite sequentially to end in the left atrium (LA).
\end{abstract}

The resistance of a given vessel in the model is dependent on vessel dimensions (length and cross-sectional area). Changes in vessel dimensions occur in response to changes in lung volume and intravascular pressure $\left(\mathrm{P}_{\mathrm{v}}\right)$. The original multibranch model was developed between 1987 and 1989, when microprocessors operated at $4.77 \mathrm{MHz}$. At the time, each extra-alveolar vessel was divided into twenty-five segments. This was done in order to shorten the time needed to go through the thousands of calculations and iterations needed to produce a stable solution (which at the time, took several minutes per one set of data). With the development of faster microprocessors, the number of segments of each extra-alveolar vessel was gradually increased initially to one hundred segments and is currently set at a thousand segments. Results obtained with twenty-five segments differed from results obtained with one hundred segments at the second decimal level and results obtained with a thousand segments differed from results obtained with one hundred segments mostly at the third decimal level and are therefore, not clinically significant. Similarly, results obtained with the four-generation model when compared with the five-generation model differed only at the second decimal level and are therefore, also not clinically significant. All simulations presented in this paper were generated with the five-generation model and 1000 segment vessels (See footnote).

Cross-sectional area of each arterial $\left(A_{a}\right)$ and venous $\left(A_{v}\right)$ segment is calculated based on the transmural pressure $\left(\mathrm{P}_{\mathrm{tm}}\right)$ across that segment, $\mathrm{P}_{\mathrm{tm}}$ being intravascular minus perivascular pressure $\left(\mathrm{P}_{\mathrm{x}}\right)$. The characteristic behaviour of $\mathrm{A}_{\mathrm{a}}$ as a function of $\mathrm{P}_{\mathrm{tm}}$ was derived from data obtained by Smith and Mitzner (S3) and Maloney et al (S4) and described in detail by Bshouty and Younes (S1). It is expressed by the following linear relationship,

$$
A_{a}=A_{a(0,35)} \cdot\left(0.2008+0.0228 \cdot P_{t m}\right)
$$

Where $A_{a(0,35)}$ is the cross sectional area of a given arterial vessel segment defined at a transpulmonary pressure $\left(\mathrm{P}_{\text {tp }}\right)$ of $\mathrm{O}$ and $\mathrm{P}_{\text {tm }}$ of $35 \mathrm{cmH}_{2} \mathrm{O}$ (a reflection of vessel dimensions under standardized conditions). The characteristic behaviour of $\mathrm{A}_{\mathrm{v}}$ as a function of $\mathrm{P}_{\mathrm{tm}}$ was also derived from data obtained by Smith and Mitzner (S3) and described in detail by Bshouty and Younes (S1). It is expressed by the following curvilinear relationship,

$$
A_{v}=1.0006 \cdot \frac{A_{v(0,35)}}{1+2.4307 \cdot e^{-0.2355 \cdot P_{t m}}}
$$

where $A_{v(0,35)}$ is the cross sectional area of a given venous vessel segment defined at a $\mathrm{P}_{\text {tp }}$ of $\mathrm{O}$ and $\mathrm{P}_{\mathrm{tm}}$ of $35 \mathrm{cmH}_{2} \mathrm{O}$ (again, a reflection of vessel dimensions under standardized conditions). Perivascular pressures of the first three pulmonary arterial and venous generations (extra-alveolar extraparenchymal vessels) were assumed equal to pleural pressure $\left(\mathrm{P}_{\mathrm{pl}}\right)$. Perivascular pressures of extra-alveolar intraparenchymal vessels are affected by both lung volume (and hence, $\mathrm{P}_{\mathrm{tp}}$ ) and $\mathrm{P}_{\mathrm{y}}$. The relationship between $\mathrm{P}_{\mathrm{x}}$ of extra-alveolar intraparenchymal vessels and $\mathrm{P}_{\mathrm{v}}$ was also derived from data obtained by Smith and Mitzner (S4). The following relationship was used for both arteries and veins,

$$
P_{x}-P_{p l}=a+b \cdot e^{e \cdot\left(P_{v}-P_{p l}\right)}
$$

The parameters $\mathrm{a}, \mathrm{b}$, and $\mathrm{c}$ were dependent on whether the vessel segment was arterial or venous and all three parameters varied linearly with $\mathrm{P}_{\text {tp }}$ (for details see reference S1).

Vessel segmental lengths (1) of the first three arterial and venous generations were assumed constant and independent of lung volume (extraparenchymal vessels). The segmental length of extra-alveolar intraparenchymal vessels was exclusively a function of lung volume and hence, of $\mathrm{P}_{\text {tp }}$ and lung compliance $\left(\mathrm{C}_{\mathrm{L}}\right)$. This relationship was also derived from data obtained by Smith and Mitzner (S3). The following relationship was used for both arteries and veins,

$$
l=\frac{l_{0,35} \cdot\left[1-\left(1-V_{M}\right) \cdot e^{-C_{L} \cdot P_{t p}}\right]^{\frac{1}{3}}}{0.7368}
$$

where $\mathrm{l}_{0,35}$ is the vessel segment length at a $\mathrm{P}_{\text {tp }}$ of $\mathrm{O}$ (again a reflection of vessel characteristics under standardized conditions), $V_{M}$ is minimal lung volume (at $\mathrm{P}_{\mathrm{tp}}=0$ ) as a fraction of total lung capacity (for details see reference $\mathrm{S} 1$ ).

In the current simulations, $\mathrm{P}_{\mathrm{pl}}$ at the LA level was assumed equal to $-5 \mathrm{~cm} \mathrm{H}_{2} \mathrm{O}$ reflecting normal lungs at end-expiration. Pleural pressure for vessels above the LA was decreased by $0.55 \mathrm{cmH}_{2} \mathrm{O}$ per $\mathrm{cm}$ height and increased by the same amount for vessels below the LA (S5). From dimensional changes, resistance of each segment was calculated assuming laminar flow. Total resistance of each vessel was calculated using numerical integration over the length of the vessel (1000 segments per vessel in the model).

The characteristic behaviour of the pulmonary capillary bed was modelled after the sheet model of Fung and Sobin (S6, S7). $\mathrm{P}_{\mathrm{x}}$ for the capillary bed was assumed equal to alveolar pressure $\left(\mathrm{P}_{\mathrm{al}}\right)$. Details of capillary resistance calculations, under different zone conditions, and recruitment and derecruitment at the capillary level are beyond the scope of this paper. These were described in detail by Bshouty and Younes (S2).

The effect of gravity was accounted for by assigning the model a certain height (in the current simulations $20 \mathrm{~cm}$ ) representing an average adult lung height in the supine position. All pressures were referenced to the LA. Flow in the model was assumed laminar and nonpulsatile.

The model was developed to represent 15 orders of pulmonary arteries between the main pulmonary artery and the capillaries and 15 orders of pulmonary veins between the capillaries and the left atrium according to Huang et al (S8). Each resistance in the model may be viewed not as a single vessel but representative of many vessels that reside at the same hydrostatic level. The first-generation vessel (arterial and venous in the current model) represents the cumulative resistances of extra-alveolar extraparenchymal vessels generations one to three. The second generation vessels in the model represent the cumulative resistances of extra-alveolar intraparenchymal vessels 


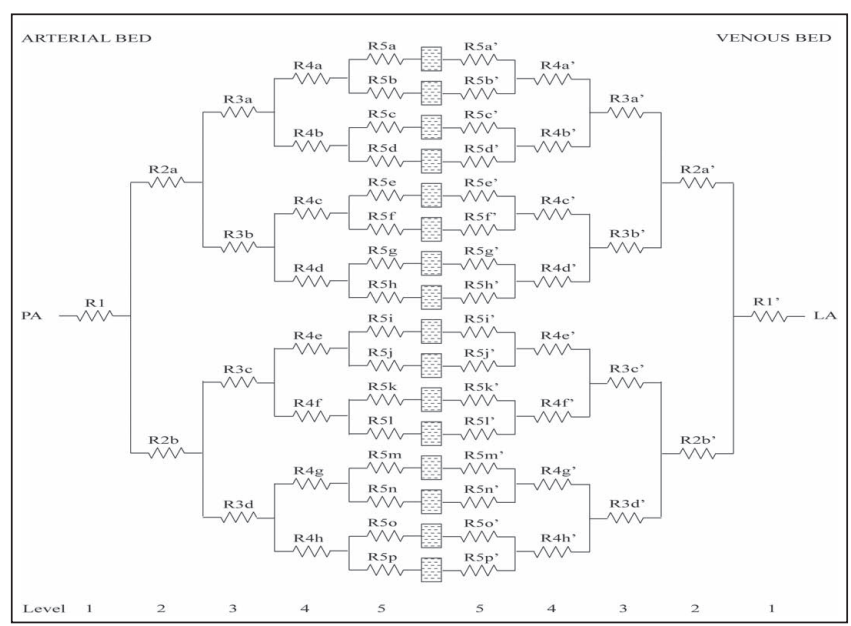

Figure S1) Multibranch model of the pulmonary circulation. The dashed rectangles in the center represent the capillary bed. Left of the capillary bed is the arterial system. Starting with the pulmonary artery (PA), the arterial system bifurcates sequentially to form five arterial generations (up to 16 parallel channels). Right of the capillary bed the pulmonary venous system recombines sequentially ending in the left atrium (LA)

generations four to six. Each generation in the model represents three generations in the human lung so that the fifth generation in the model represents lung vessel generations thirteen to fifteen.

Although the wall structure of the pulmonary arteries varies considerably between the main pulmonary artery all the way down to the precapillary terminal arteries (S9), the distensibility of the vessels is independent of vessel diameter (S9-S12). Hence, the distensibilities of the arterial vessels were assumed equal across the five arterial generations. Since a similar observation was seen in pulmonary veins (S13), the distensibilities of the venous vessels across the five venous generations were also assumed equal, under normal conditions.

\section{Model adaptation to humans}

The model was originally developed based on data obtained in open chested dogs. Lung compliance was changed to equal what is normally observed in humans (S14) after correcting static compliance to liter (L) per $\mathrm{cmH}_{2} \mathrm{O}$ according to the following relationship,

$$
C_{L}=0.002617 \cdot H t-0.1410
$$

where $\mathrm{Ht}$ is patient height in $\mathrm{cm}$.

Because the vascular structure of the pulmonary circulation as seen on pathology is similar in both humans and dogs, the characteristic behaviour (cross-sectional area as a function of $\mathrm{P}_{\mathrm{tm}}$ and vessel length as a function of lung volume) of extra-alveolar arteries and veins were kept the same. A similar assumption was used for the characteristic behaviour of the capillary bed.

The longitudinal distribution of pulmonary vascular resistance along the vascular bed was based on data obtained by Huang et al (S8). An average diameter ratio of parent to daughter vessel of 1.56 was assumed for all pulmonary arteries and 1.58 for all pulmonary veins under normal conditions. An average length ratio of parent to daughter vessel of 1.49 was assumed for all pulmonary arteries and 1.50 for all pulmonary veins. An average branching ratio (daughter vessels to parent vessel) of 3.36 was used for all pulmonary arteries and 3.33 for veins. These ratios were obtained at a perfusion pressure of $3 \mathrm{cmH}_{2} \mathrm{O}$ while alveolar gas pressure was maintained at $10 \mathrm{cmH}_{2} \mathrm{O}$ and pleural pressure was zero (S8). Based on the above, baseline vessel resistance of each vessel in each generation was calculated. Using the characteristic behaviour of arteries and veins (equations 1, 2, and 4) baseline resistances were adjusted to the current model standardized conditions of $\mathrm{P}_{\mathrm{tp}}$ of $\mathrm{O} \mathrm{cmH}_{2} \mathrm{O}$ and $\mathrm{P}_{\mathrm{tm}}$ of $35 \mathrm{cmH}_{2} \mathrm{O}$.

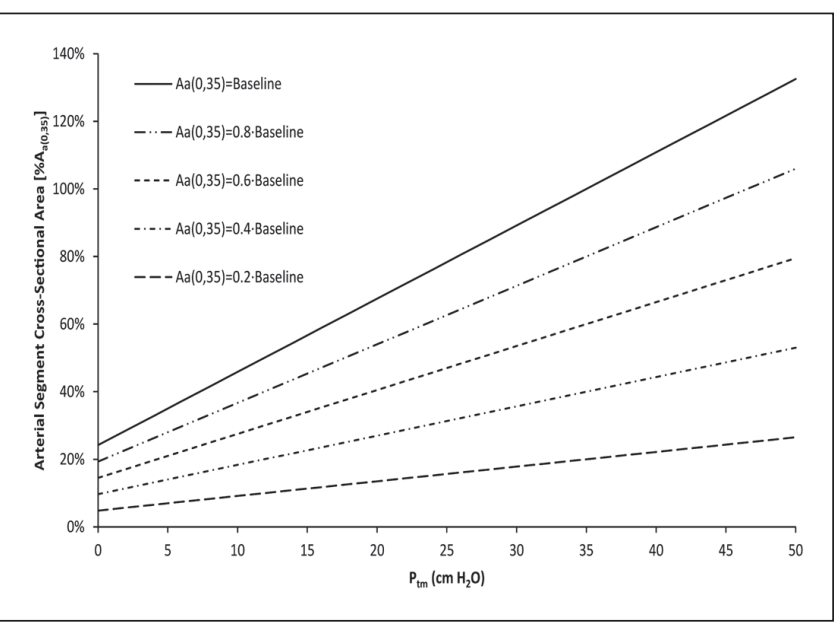

Figure S2) Correlation between vascular cross-sectional area [as a per cent of baseline, $A_{a(0,35)}$, defined at a transpulmonary pressure $\left(P_{t p}\right)$ of zero and vessel transmural pressure $\left(P_{t m}\right)$ of $\left.35 \mathrm{cmH}_{2} \mathrm{O}\right]$ and $P_{t m}$ of the arterial bed. Solid line represents baseline (normal) vessel characteristics. Interrupted lines represent various degrees of vascular compromise ranging from $0.8 \bullet \mathrm{A}_{a(0,35)}$ to $0.2 \bullet \mathrm{A}_{a(0,35)}$, in steps of $0.2 \bullet \mathrm{A}_{a(0,35)}$. Notice that as vascular compromise increases, vessel compliance decreases

Transition from the above dimensional characteristics to provide actual resistances along the pulmonary vascular bed was achieved by obtaining a PAPm of $15 \mathrm{mmHg}$ at a CO of $6.45 \mathrm{~L} / \mathrm{min}$ (Cardiac index $3.38 \mathrm{~L} / \mathrm{min} / \mathrm{m}^{2}$ ) and a LAP of $5 \mathrm{mmHg}$ reflecting the normal pulmonary circulation in an adult subject $175 \mathrm{~cm}$ tall and weighing $75 \mathrm{~kg}$ (S15). The contribution of capillary resistance to total resistance under these conditions was approximately $16 \%$ with the arterial and venous systems contributing equally to the remaining resistance (S16). Although in the current simulations a height of $175 \mathrm{~cm}$ and weight of $75 \mathrm{~kg}$ were used, the model accepts a height range of $30 \mathrm{~cm}$ to $225 \mathrm{~cm}$ and a weight range of $2 \mathrm{~kg}$ to $300 \mathrm{~kg}$. Baseline resistances in the model are adjusted automatically to accommodate different body sizes. This is achieved by assuming that at a normal cardiac index of 3.38, all subjects (irrespective of height and weight) with a normal pulmonary circulation have a PAPm of $15 \mathrm{mmHg}$ at a LAP of $5 \mathrm{mmHg}$ (S15).

\section{Model adaptation to PAH}

The predominant cause of the increase in pulmonary vascular resistance in PAH is loss of vascular luminal cross-sectional area due to vascular remodeling produced by excessive hypertrophy and proliferation of the intima, media, and adventitia of small pulmonary arteries (usually $<2000 \mu \mathrm{m}$ in diameter) (S17). Vasoconstriction plays a role in only a minority of cases as less than $13 \%$ of the patients are vasoreactive at the time of investigation (S18). Hence, when simulating PAH, vascular compromise in the model was confined to the fifth arterial generation (representing generations thirteen to fifteen in the human lung). Because the same vessels are involved in regulating the regional distribution of blood flow in the lung, they were also assumed the site of vasoconstriction (S19). Although, smooth muscle tone, representing vasoconstriction, could be added to any vessel in the model (For a complete description of modeling smooth muscle tone see reference [S1]).

Initially, simulations were performed without the addition of vasoconstriction. Simulation of PAH was achieved by assigning the precapillary (fifth arterial generation) vessels increasing levels of vascular compromise. Vascular compromise was imposed by assuming a smaller cross-sectional area for the fifth arterial generation at $\mathrm{P}_{\mathrm{tp}}=0$ and $\mathrm{P}_{\mathrm{tm}}=35 \mathrm{cmH}_{2} \mathrm{O}$. In the current simulation, vascular compromise was applied equally to all sixteen precapillary vessels. The characteristics of all other vessels were assumed normal. 
There are no human data comparing pulmonary arterial distensibility of healthy subjects to that in patients with pulmonary arterial hypertension. In a study by Molthen RC et al (S12), arterial distensibility (over a pressure range of $5 \mathrm{mmHg}$ to $30 \mathrm{mmHg}$ ) of SpragueDawley rats exposed to 21 days of hypoxia was compared with controls. The relationship between vessel diameter and pressure remained linear in arteries ranging in size from $70 \mu \mathrm{m}$ to $2800 \mu \mathrm{m}$, and distensibility (the slope of the relationship) dropped from 0.028 to 0.015 . This fixed drop in distensibility is likely the result of the group (SpragueDawley rats) and study conditions (degree of exposure) homogeneity. In patients suffering from pulmonary arterial hypertension, the decline in distensibility is likely gradual and correlates with disease progression. As shown in equation 1 , the relationship between $A_{a}$ and $P_{t m}$ is linear. Because $A_{a(0,35)}$ is multiplied by both slope and intercept, reducing $A_{a(0,35)}$ does not only decrease the intercept (ie, parallel shift) of the relationship between $\mathrm{A}_{\mathrm{a}}$ and $\mathrm{P}_{\mathrm{tm}}$, but also the slope of this relationship reflecting a change in vascular compliance. As shown in Figure S2, compared with baseline (solid line) a progressive decline in vascular cross-sectional area in steps of 0.2 (from $0.8 \bullet \mathrm{A}_{\mathrm{a}[0,35]}$ to $\left.0.2 \bullet \mathrm{A}_{\mathrm{a}[0,35]}\right)$ is associated with a progressive and proportional decline in both intercepts and slopes thus describing a change in the passive characteristics of these vessels (hence, the use of vascular compromise in this article rather than simple narrowing). This type of behaviour is anticipated even when merely based on simple proliferation of vascular wall layers (media and intima).

Simulation of vasoconstriction without vascular compromise is achieved by keeping $A_{a(0,35)}$ at baseline. In this case, compromise is active and occurs because of an effective reduction in $\mathrm{P}_{\mathrm{tm}}$ (equivalent to the amount of applied vasoconstriction) along the original curve (again, for details on the simulation of smooth muscle tone see reference S1).

\section{Determination of PAPm and total PVR}

As mentioned above, baseline resistances of each vessel in each generation are assigned under standardized conditions $\left(\mathrm{P}_{\mathrm{tp}}=0\right.$ and $\left.\mathrm{P}_{\mathrm{tm}}=35 \mathrm{cmH}_{2} \mathrm{O}\right)$ and adjusted automatically to accommodate different patient heights and weights. The operator enters three groups (general, patient specific, and hemodynamic) of data into the model. General data includes the reference point for pressure measurement (top or bottom of the lung, or LA) and the tolerance level for a given run (see below). Patient specific data includes patient height, weight, lung height, lung compliance, and lung volume at a $\mathrm{P}_{\text {tp }}=0$. Hemodynamic data includes the point of measurement during the respiratory cycle (as determined by $\mathrm{P}_{\mathrm{al}}$ and $\mathrm{P}_{\mathrm{pl}}$ ) and $\mathrm{LAP}$ and CO. The

\section{REFERENCES}

S1. Bshouty Z, Younes M. Distensibility and pressure-flow relationship of the pulmonary circulation. I. Single-vessel model. J Appl Physiol 1990;68:1501-3.

S2. Bshouty Z, Younes M. Distensibility and pressure-flow relationship of the pulmonary circulation. II. Multibranched model. J Appl Physiol 1990;68:1514-27.

S3. Smith JC, Mitzner W. Analysis of pulmonary vascular interdependence in excised dog lobes. J Appl Physiol 1980;48:450-67.

S4. Maloney JE, Rooholamini SA, Wexler L. Pressure-diameter relations of small blood vessels in isolated dog lung. Microvasc Res 1970;2:1-12.

S5. Tawhai MH, Nash MP, Lin CL, Hoffman EA. Supine and prone differences in regional lung density and pleural pressure gradients in the human lung with constant shape. J Appl Physiol 2009; 107:912-20

S6. Fung YC, Sobin SS. Elasticity of the pulmonary alveolar sheet. Circ Res 1972;30:451-69.

S7. Fung YC, Sobin SS. Pulmonary alveolar blood flow. Circ Res 1972;30:470-90.

S8. Huang W, Yen RT, McLaurine M, Bledsoe G. Morphometry of the human pulmonary vasculature. J Appl Physiol 1996;81:2123-33.

S9. Cox RH. Comparison of mechanical and chemical properties of extra- and intralobar canine pulmonary arteries. Am J Physiol 1982;242:H245-53.

S10. al-Tinawi A, Madden JA, Dawson CA, Linehan JH, Harder DR, Rickaby DA. Distensibility of small arteries of the dog lung. J Appl Physiol 1991;71:1714-22.

S11. Karau KL, Molthen RC, Dhyani A, Haworth ST, Hanger CC, operator is given the opportunity to modify any baseline characteristics of any given vessel (including the addition of vasoconstriction to any vessel) in the model before proceeding with the calculations. PAPm and total PVR are determined by iteration. Initially, flow is assumed to be equally distributed across all vascular channels. Given the initial distribution of resistances, vascular pressures across the pulmonary circulation are calculated. After accounting for the effects of gravity and $\mathrm{P}_{\mathrm{x}}$ changes, transmural pressures at each segment of each vessel are calculated and using numerical integration total resistance of each vessel is recalculated. Using the new distribution of resistances, a new distribution of flows is recalculated with a new distribution of pressures. The computer continues cycling (iterating) through the above process until a stable solution is reached when flows, pressures and resistances stabilize (stop changing) across the whole vascular bed (in the current simulations less than $0.1 \%$ ). The output includes the distribution of individual pulmonary vascular flows, arterial, capillary, and venous resistances across the whole pulmonary circulation including summary data of PAPm, PVR, upstream (arterial), middle (capillary), and downstream (venous) resistances.

\section{Effect of branching on model predictions}

To assess whether model predictions are affected by the levels of branching, results obtained with the four (original) and five generations models, over the whole range of cardiac outputs and left atrial pressures reported here, were compared. In the four generations model, adaptations to humans and PAH (see above) were similar to the five generations model except for the following differences. In the four generations model, the first generation represented the first three generations in human lung and the rest of the generations (two, three and four), each represented four generations in the human lung so that the total number of generations represented was the same between the two models (15). Simulation of PAH was achieved by compromising the fourth generation vessels in the four generations model, and similarly, vasoconstriction was applied to the fourth-generation vessels. Simulation results obtained with the four and five generations models were identical to the second decimal point and hence, were not clinically significant. All simulations and results presented here were generated using the five-generation model.

FOOTNOTE: The latest version of the simulation program includes both a five- and a 15-generation (16,384 parallel vessels) model, with each vessel divided into 10,000 segments. The program is available, free of charge and upon request, to all $\mathrm{PH}$ centres.

Roerig DL, Johnson RH, Dawson CA. Pulmonary arterial morphometry from microfocal X-ray computed tomography. Am J Physiol Heart Circ Physiol 2001;281:H2747-56.

S12. Molthen RC, Karau KL, Dawson CA. Quantitative models of the rat pulmonary arterial tree morphometry applied to hypoxiainduced arterial remodeling. J Appl Physiol 2004;97:2372-84.

S13. al-Tinawi A, Clough AV, Harder DR, Linehan JH, Rickaby DA, Dawson CA. Distensibility of small veins of the dog lung. J Appl Physiol 1992;73:2158-65.

S14. Galetke W, Feier C, Muth T, Ruehle KH, Borsch-Galetke E, Randerath W. Reference values for dynamic and static pulmonary compliance in men. Respir Med 2007;101:1783-9.

SE15. Jegier W, Sekelj P, Auld PA, Simpson R, McGregor M. The relation between cardiac output and body size. Br Heart J 1963;25:425-30.

S16. Hakim TS, Michel RP, Chang HK. Partitioning of pulmonary vascular resistance in dogs by arterial and venous occlusion. J Appl Physiol 1982;52:710-5.

S17. Palevsky HI, Schloo BL, Pietra GG, Weber KT, Janicki JS, Rubin E, Fishman AP. Primary pulmonary hypertension. Vascular structure, morphometry, and responsiveness to vasodilator agents. Circulation 1989;80:1207-21.

S18. Sitbon O, Humbert M, Jaïs X, Ioos V, Hamid AM, Provencher S, Garcia G, Parent F, Hervé P, Simonneau G. Long-term response to calcium channel blockers in idiopathic pulmonary arterial hypertension. Circulation 2005;111: 3105-11.

S19. Archer S, Rich S. Primary pulmonary hypertension: A vascular biology and translational research "Work in progress". Circulation 2000;102:2781-91. 


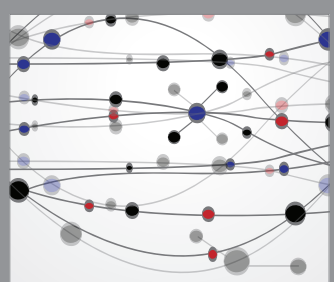

The Scientific World Journal
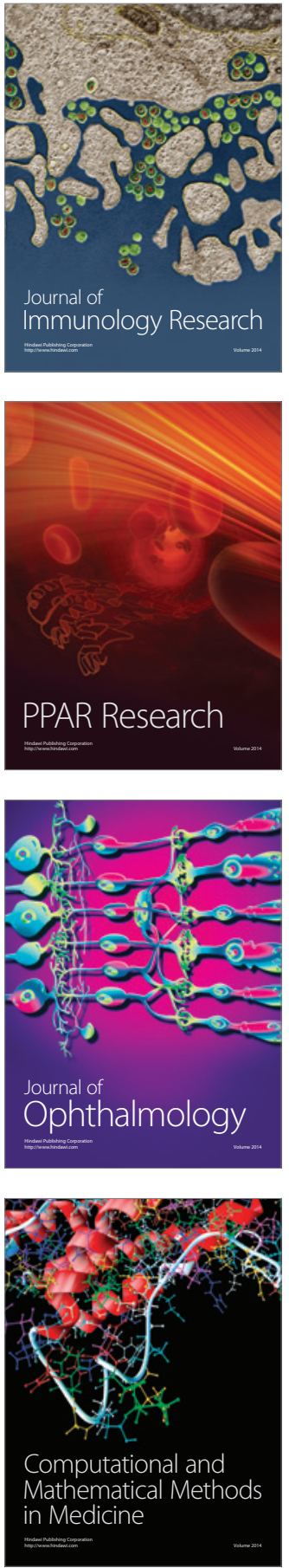

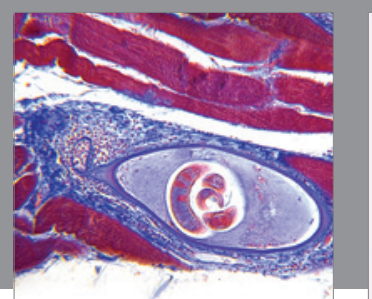

Gastroenterology Research and Practice

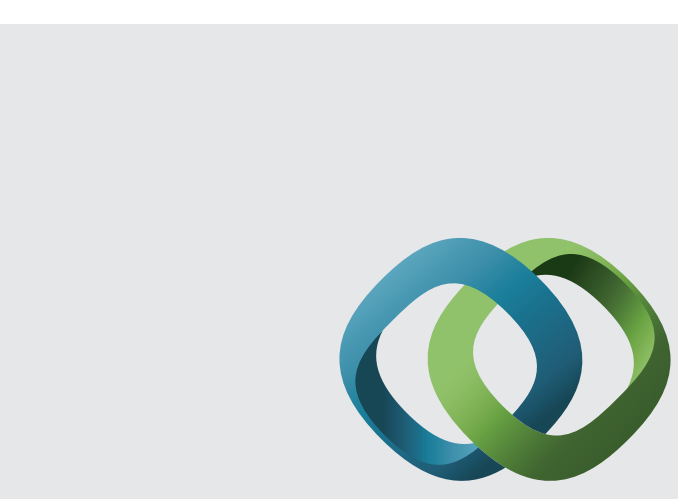

\section{Hindawi}

Submit your manuscripts at

http://www.hindawi.com
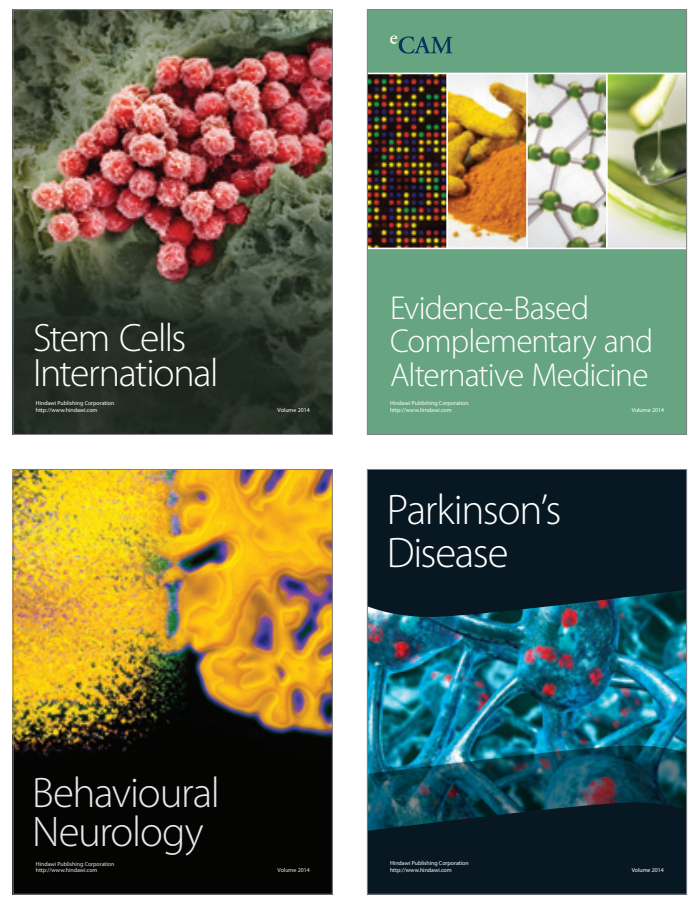
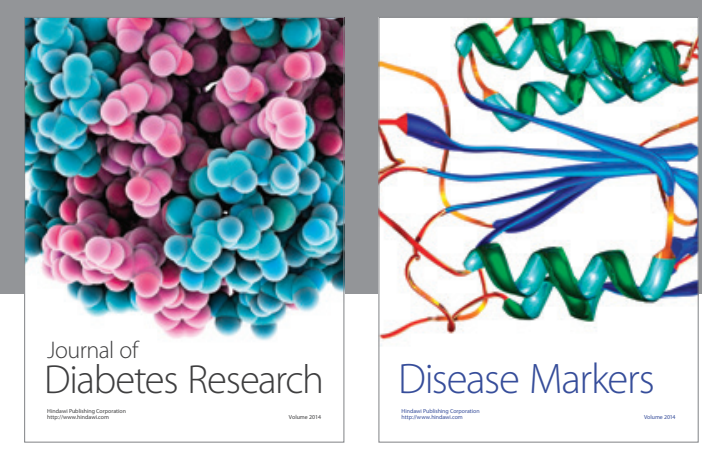

Disease Markers
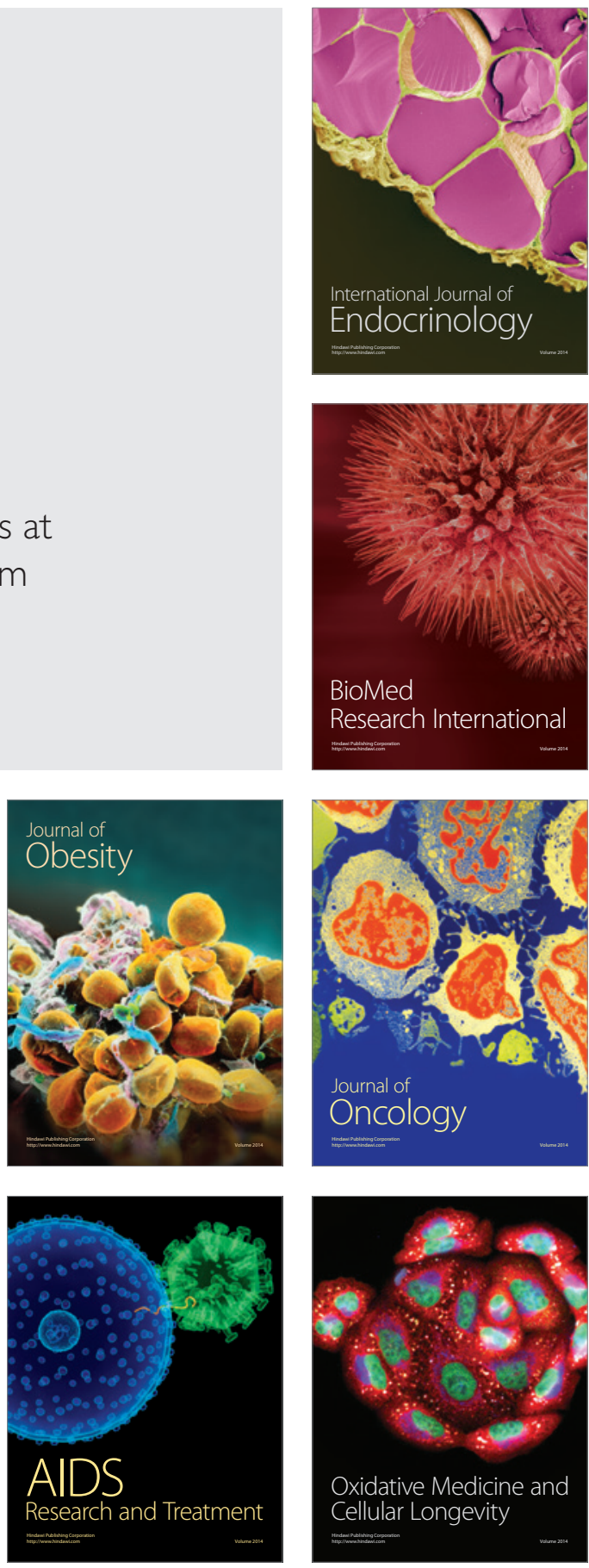